\title{
The Center for Advanced Fire Safety Science and Technology for Buildings-Overview and Summary
}

\author{
Masahiro Morita \\ Tokyo University of Science, Japan
}

Thank you very much for attending the first symposium of the $21^{\text {st }}$ Century COE program titled "The Center for Advanced Fire Safety Science and Technology for Buildings."

I will provide an overview of the program. My explanation is intended to provide you with a better understanding of the program.

The Center for Fire Science and Technology currently has five dedicated staff members. They are Prof. Wakamatsu, Dr. Matsuyama, Dr. Mizuno, Prof. Sugahara, and Prof. Yoshikawa. Prof. Sugawa and I are working on the program on a double-duty basis.

The Tokyo University of Science comprises three colleges: Tokyo College, Yamaguchi College, and Suwa College. Cutting across the three colleges are the research centers: The Research Institute for Science and Technology, The Research Institute for Biological Science, and The Research

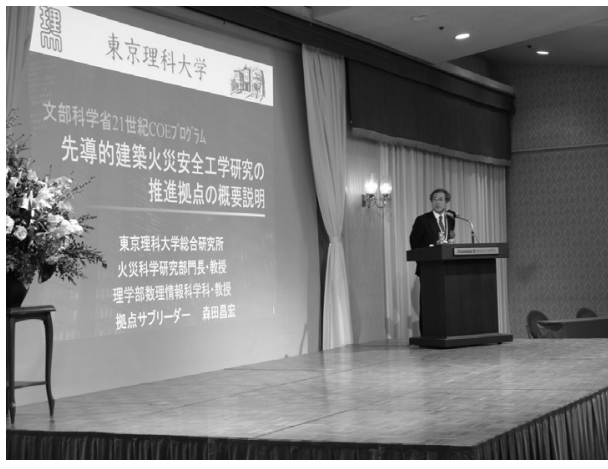

Photo 1.4.1 Prof. Morita

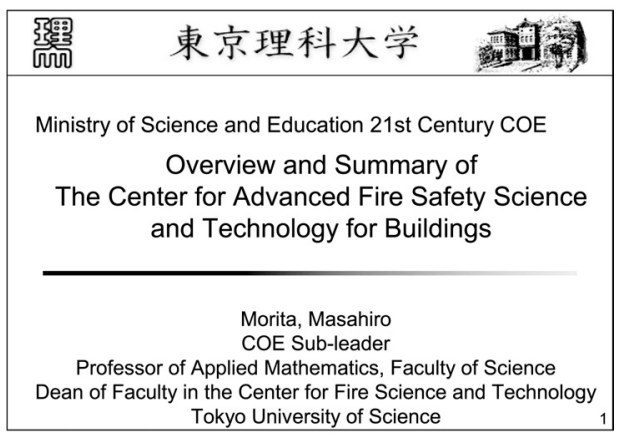

Figure 1.4.1

Education Organization for Information Science and Technology. The Center for Fire Science and Technology is a component of The Research Institute for Science and Technology.

The Center for Fire Science and Technology began operation in 1981, the year of the centennial anniversary of our university, with Prof. Wakamatsu, Prof. Handa, Prof. Kawagoe, and other staff. As an assistant at that time, I participated in the center in the capacity of assistant researcher. Almost 22

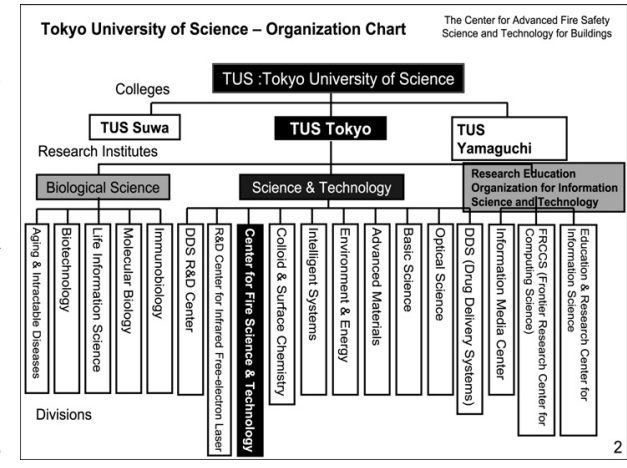

Figure 1.4.2 
years have passed since then. Now, I am working on the center as the leader.

When we were in search of a way to achieve further advancement, Prof. Wakamatsu, the former leader of the center, applied for COE program grants sponsored by the Ministry of Education, Culture, Sports, Science and Technology. The proposal has been successfully accepted by the ministry as you already know.

The COE project will be a joint effort of one research institute and two faculty majors, namely, the Center for Fire Science and Technology, Department of Architecture, Faculty of Science and Technology, and Faculty of Engineering .

In the $21^{\text {st }}$ Century COE budgeted for FY 2003, the ministry selected sites that demonstrated significant research and education in five different fields. Our university was selected in one of the five, the field of machine, civil, architectural, or other engineering. Of the 23 proposals selected, we were the only private university selected in the field of architecture.

The selection standards were as follows.

1. The center/site has demonstrated significant accomplishments and is expected to grow and develop further in the future. (We have 22 years of

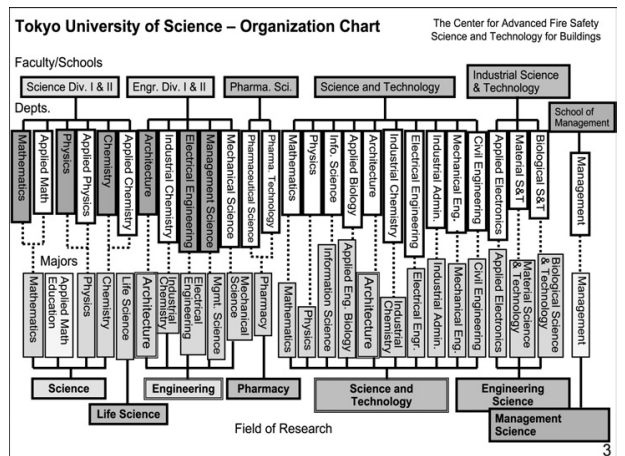

Figure 1.4.3

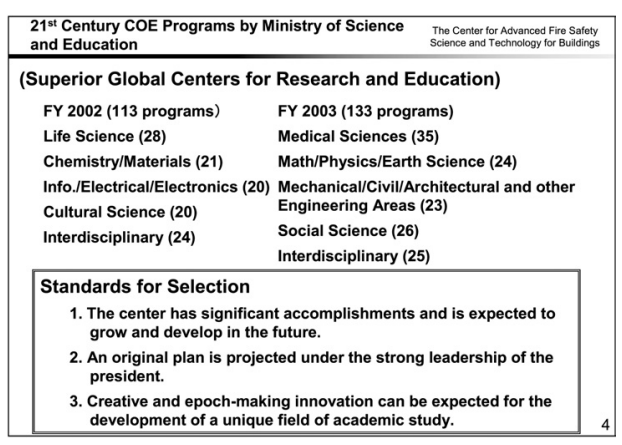

Figure 1.4.4 experience.)

2. An original plan is projected under the strong leadership of the president. (We know that the president has shown strong leadership and extensive cooperation in this project.)

3. Creative and epoch-making innovation can be expected from the development of a unique field of academic study. (England, the United States, and Japan are the world's three major sites for the study of fire science. This university has become one of the best places for research activities in the world, thanks to the efforts made to this day by our scholars and researchers.)

With those standards in mind, ministry officials accepted our submission and selected the university for the COE program. 
The left side represents research activities and the right side represents education activities, as shown in Figure 1.4.5.

The course for building fire prevention was already started before 1980 for education purposes in the Faculty of Engineering and the Faculty of Science and Technology. Then in 1981, the Center for Fire Science and Technology was established for research

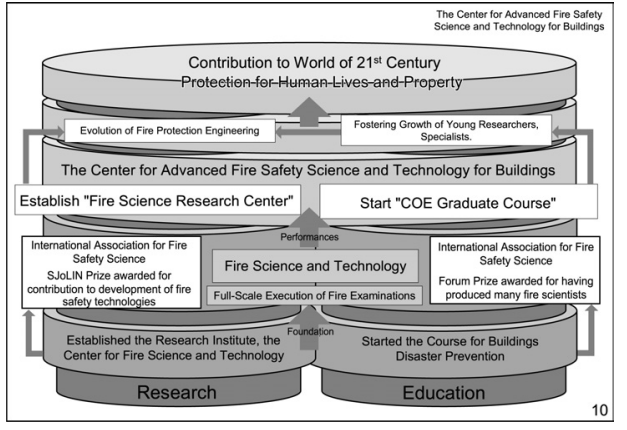

Figure 1.4.5 purposes. From that time onwards, the university began to focus its resources on the study of fire safety.

In 1994, IAFSS (International Association of Fire Safety Science) honored us for "having contributed to the advancement of fire safety technology." In 1997, IAFSS again honored us for "having produced many fire researchers."

During that time, our technology gradually advanced and the number of researchers grew, making this university one of the best organizations in the world for research and education in the field of fire science.

In 1981, we published the international journal for Fire Science and Technology, in order to promote linkage between research and education. In addition, we performed full-scale fire examinations on several special fire events. These are some of our achievements made to this day among many others.

Adoption of our university as the site for COE made us decide to establish the Research Center for Fire Science and Technology. A large test facility, which provides sufficient capability to perform several different types of tests, will be built at the center by the end of FY this year. Furthermore, we are initiating a COE graduate course.

Our mission at the COE is to develop fire safety science and foster the growth of the next generation of young researchers and specialists. Even after the end of the five-year plan for the COE, we will continue these efforts to uphold the current mission. Creation of the Research Center for Fire Science and Technology will be a great encouragement for us upon which we can make this long-standing commitment to fire science.

Now, I want to explain the background. Questions were raised as to what would happen if a serious fire broke out in one of the large-scale re-development districts, such as Tokyo-Shiodome (population: 150,000) and Roppongi (population: 50,000). We will take into account such background in performing our study of fire safety.

Here(Figure 1.4.6), in this overview, the major areas of fire safety engineering analysis for a building are presented. Our study consists of fire behavior, firefighting capability, 
structural fire resistance, smoke behavior, and evacuation. We would also like to extend our study to urban fires.

Our activities include case studies in each area of fire safety. We will study structural fire resistance from the $9 / 11$ terrorist attacks in 2001, frame spread characteristics from the high-rise building fire in São Paulo, Los Angeles, and fire behavior and human

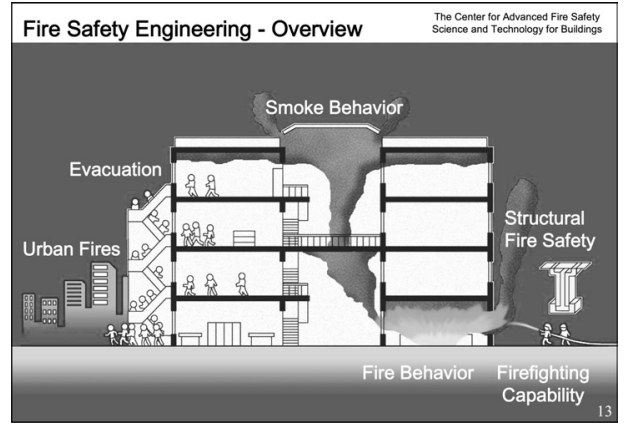

Figure 1.4.6 behavior during evacuation from a special case fire that occurred in one corner of a high-rise condominium.

There are two key elements of utmost importance in the process of creating the COE. One is to establish the Research Center and the other is to start a graduate course. They are the top priority issues in our planning of the COE. We are doing our best to study the areas of high potentiality, with the hope of attracting many young researchers.

Listed here(Figure 1.4,7) are major programs in our education plan. Those education programs are also a priority in our COE Creation Plan. However, the focus is on two programs: promote international education in cooperation with overseas institutions and support the growth of young researchers.

Our predecessors contributed to the advancement of fire science in our university. We can name Prof. Handa, Prof. Kawagoe, Prof. Hamada, and Prof. Moriwaki as the leading contributors. We can carry the COE program forward based upon the accomplishments of these distinguished researchers. However, we have goals to accomplish, a great leap forward in the evolution of fire science.

We also want to send valuable messages and materials from Japan to the world and into the future of the $21^{\text {st }}$ century in such a way that the Research Center for Fire Science and Technology takes the initiative in those actions. For these purposes, we 
have members assigned to each position of the center such as the COE leader, the COE sub-leader, and the COE researchers, in addition to the visiting professors, COE-PDs, and COE technicians invited to the center, whose roles are an essential part of our activities. We are asking them to rend their cooperation as active members of the $\mathrm{COE}$ program.

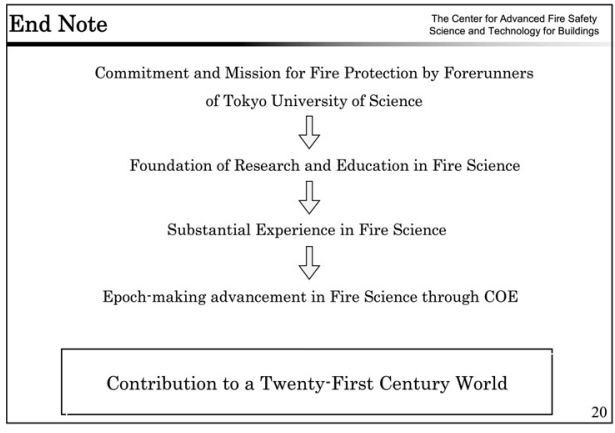

Figure 1.4.9

This is a simple overview of the program. Thank you very much for your time. 